\title{
Familial Pancreatic Cancer at Elderly Siblings in Japan
}

Yohei Kashimoto $^{1}$, Morikazu Onji ${ }^{2}$, Satoshi Takeji ${ }^{3}$, Shin Yamamoto ${ }^{4}$, Teruki Miyake ${ }^{5}$,Takahide Uehara ${ }^{6}$, Keitaro Kawasaki ${ }^{7}$, Takatoshi Murakami ${ }^{8}$, Jiro Miyaike ${ }^{9}$, Masaki Oomoto ${ }^{10}$, Kenji Bando ${ }^{11}$, Norio Horiike ${ }^{12}$, Masanori Abe ${ }^{13}$, Teru Kumagi ${ }^{14}$

\begin{abstract} Keywords: Cancer risk, Elderly siblings, Familial pancreatic cancer.

Euroasian Journal of Hepato-Gastroenterology (2019): 10.5005/jp-journals-10018-1296

\section{INTRODUCTION}

Famil milial pancreatic cancer (FPC) is defined as at least two firstdegree relatives with pancreatic cancer (PC) that does not meet the criteria of other hereditary cancer syndromes. Japan initiated a nationwide FPC registry in 2014 and it seems that younger onset is common in FPC. ${ }^{1}$ This age-related phenomenon has also been supported by FPC from other countries. ${ }^{2,3}$ However, we experienced two cases of FPC in siblings aged 87 years and 90 years. The PC of these two patients was also confirmed at autopsy as well. They also had a direct family history of pancreatic cancer as their father and brother also suffered from same cancer.
\end{abstract}

Two female siblings aged 87 and 90 years were clinically diagnosed as pancreatic cancer by abdominal ultrasonography and abdominal contrast-enhanced CT. Pancreatic cancer of these patients was confirmed during the autopsy. Both patients shared risk factors of pancreatic cancer; old age, diabetes, and passive smoking. Strong family history of pancreatic cancer was found in these two patients as their father and younger brother were also suffering from this cancer. The present study seems to report two eldest cases of familial pancreatic cancer in siblings.

\section{CASE REPORTS}

\section{Case 1}

An 87-year-old Japanese female with complaints of abdominal pain and constipation was admitted to our hospital in March 2016. She had been suffering from type 2 diabetes mellites for almost forty years and had Hashimoto's disease. She did not require insulin but was on oral antidiabetics and thyroid replacement therapy. There has been no history of drinking alcohol or smoking cigarettes. However, her husband was a heavy smoker. She was $153 \mathrm{~cm}$ tall, and her body weight was $44.8 \mathrm{~kg}$ with body mass index (BMI) of $19.1 \mathrm{~kg} / \mathrm{m}^{2}$. Her abdomen was flat and soft. She had a dull tenderness in her right lower abdomen. She was not jaundiced. Main laboratory findings on admission revealed as follows: HbA1c $8.2 \%$, free T4 $1.13 \mathrm{ng} / \mathrm{dL}$, thyroid stimulating hormone (TSH) $4.19 \mu \mathrm{U} /$ $\mathrm{mL}$, carcinoembryonic antigen (CEA) $4.7 \mathrm{ng} / \mathrm{mL}$, carbohydrate associated antigen 19-9 (CA19-9) 200.6U/mL, s-pancreas antigen-1 $67.9 \mathrm{U} / \mathrm{mL}$. Contrast-enhanced CT showed an ovalshaped hypovascular tumor in the pancreatic body (diameter of $32 \mathrm{~mm}$ along with multiple nodules in the peritoneum). The final diagnosis was PC complicated with peritoneal dissemination (cT4, cNx,cM1, stage IV). She was under palliative care until she died 2 months later. The gross appearance of the abdomen at autopsy revealed hemorrhagic ascites, a cluster formation with adhesion by adjacent abdominal organs and tissues (Fig. 1), and dissemination of multiple white nodules in the peritoneum. Microscopic picture of the pancreas revealed a proliferation of cancer cells and abundant fibrosis. The final pathological diagnosis was well-poor differentiated adenocarcinoma of the PC (Fig. 2).
1-3,6-10,12Emeritus, Ehime University, Toon City, Japan

4,5,13 Department of Gastroenterology and Metabology, Ehime University Graduate School of Medicine, Toon City, Japan

${ }^{11}$ Department of Pathology, Saiseikailmabari Hospital, Imabari, Japan

Corresponding Author: Morikazu Onji, Ehime University, Toon City, Japan, Phone: 090-1177-9693, e-mail: morikazu.onji@gmail.com

How to cite this article: Kashimoto Y, Onji M, et al. Familial Pancreatic Cancer at Elderly Siblings in Japan. Euroasian J Hepatogastroenterol 2019;9(1):52-54.

Source of support: Nil

Conflict of interest: None

\section{Case 2}

A 90-year-old Japanese female patient (elder sister of Case 1) was hospitalized to our hospital with epigastric pain and anorexia in June 2016. She had a 40-year history of type 2 diabetes, and she was on oral antidiabetics but never required insulin. She also had Hashimoto's disease, but thyroid replacement was discontinued after normalization of thyroid hormone profiles in sera. She denied smoking tobacco or drinking alcohol. However, her husband was a heavy smoker. She was $149 \mathrm{~cm}$ tall and her body weight was $48 \mathrm{~kg}$ (BMI $21.6 \mathrm{~kg} / \mathrm{m}^{2}$ ). Physical status on admission was stable

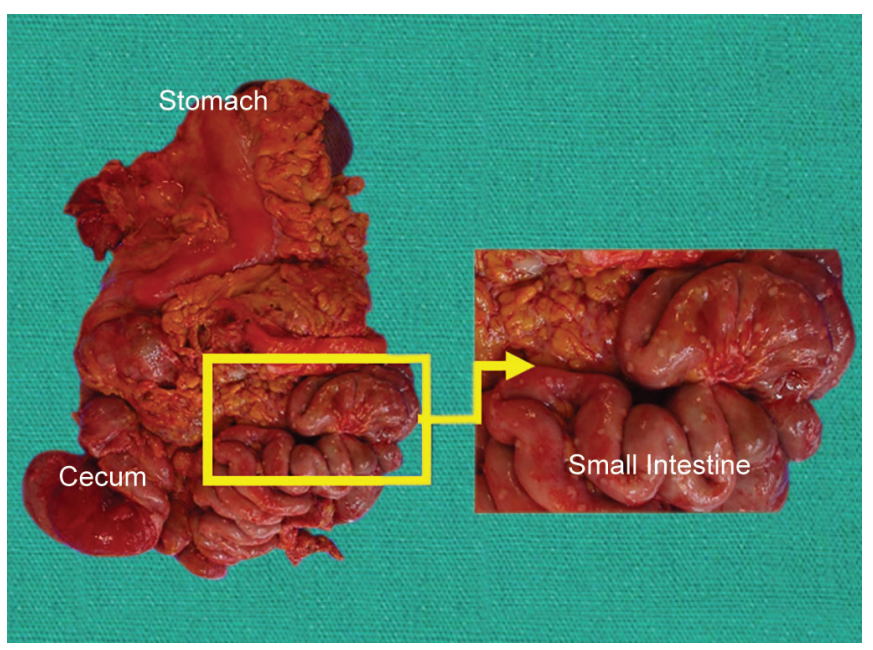

Fig. 1: Gross appearance of abdomen (Case 1)

(c) The Author(s). 2019 Open Access This article is distributed under the terms of the Creative Commons Attribution 4.0 International License (https://creativecommons. org/licenses/by-nc/4.0/), which permits unrestricted use, distribution, and non-commercial reproduction in any medium, provided you give appropriate credit to the original author(s) and the source, provide a link to the Creative Commons license, and indicate if changes were made. The Creative Commons Public Domain Dedication waiver (http://creativecommons.org/publicdomain/zero/1.0/) applies to the data made available in this article, unless otherwise stated. 


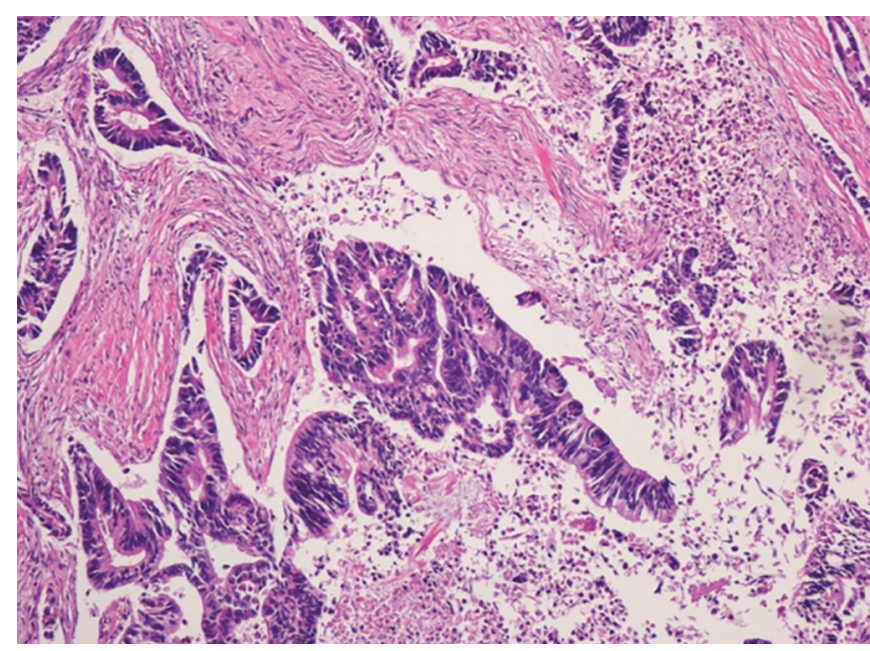

Fig. 2: Microscopic picture of pancreatic cancer (case 1)

except tenderness in her upper abdomen. She was not jaundiced. She did not have hepatomegaly or splenomegaly, and there was no palpable mass in the abdomen. Main laboratory findings on admission revealed as follows: $\mathrm{HbA} 1 \mathrm{c} 6.5 \%$, free $\mathrm{T} 41.15 \mathrm{ng} / \mathrm{dL}, \mathrm{TSH}$ $0.96 \mu \mathrm{U} / \mathrm{mL}$, thyroglobulin $77.10 \mathrm{ng} / \mathrm{mL}$, thyroglobulin antibody $592.1 \mathrm{IU} / \mathrm{mL}$, thyroid stimulating antibody $105 \%$, thyroid peroxidase antibody $10.4 \mathrm{IU} / \mathrm{mL}$, TSH receptor antibody $0.5 \mathrm{IU} / \mathrm{mL}$, CEA $5.8 \mathrm{ng} /$ $\mathrm{mL}, \mathrm{CA} 19-980.9 \mathrm{U} / \mathrm{mL}$. Contrast-enhanced CT and PET-CT revealed a tumor in the head of the pancreas at the diameter of $26 \mathrm{~mm}$. The final diagnosis was locally advanced PC (CT4, NO, M0, stage III). She initially received chemoradiation therapy, but she finally chose palliative care alone. Although metallic stent was placed in the duodenum for duodenal stenosis followed by biliary stenting for obstructive jaundice, she eventually died 15 months after initial diagnosis. On autopsy, the gross appearance of the abdomen revealed some metastatic nodules in the liver (Fig. 3). Carcinoma arising from pancreatic head invaded into the duodenum and lower bile duct with respective stents remaining. The hemorrhagic change was found in gastrointestinal tracts and uterus presumably caused by disseminated intravascular coagulation. Microscopically the main tumor was diagnosed as well differentiated tubular adenocarcinoma with a component of papillary adenocarcinoma and mucinous carcinoma (Fig. 4).
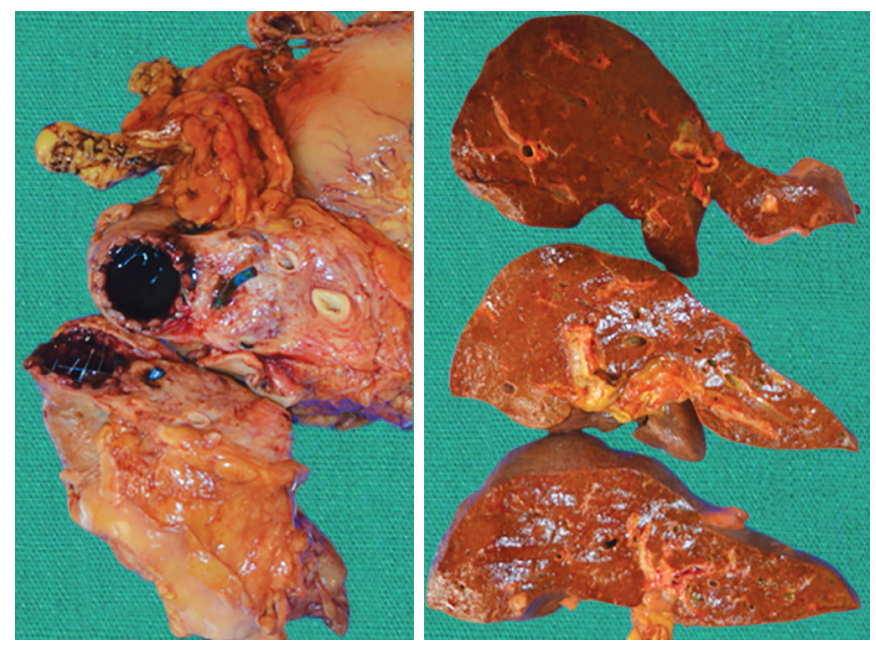

Fig. 3: Gross appearance of abdomen (case 2)
With regards to the familial tree of these two present cases, these two patients were a sibling. There were four patients with PC within the first-degree family (sisters, young brother, and father) (Flowchart 1). Notably, various cancers, breast cancer, were included in this family. Of note, eight family members of the family had been suffering from diabetes.

\section{Discussion}

PC is currently the 4th leading cause of cancer death in Japan following colon cancer, lung cancer, and stomach cancer. ${ }^{4}$ Incidence of PC is also increasing, ranked the 7th among various malignancies, and approximately 30,000 patients with PC are newly diagnosed annually. ${ }^{4}$ Although the true etiology of $P C$ is not well defined, the risk factors of PC are known, i.e., age, diabetes, smoking, alcohol consumption, and family history. ${ }^{4}$ The peak onset of PC is in the 6th and 7th decades of life. However, the onset of hereditary malignant tumors, hereditary non-polyposis colorectal cancer and multiple endocrine neoplasia type 1 for instance, is significantly younger than sporadic malignant tumors. ${ }^{1,2}$ As for FPC, there are reports to show the younger onset in comparison to sporadic PC. ${ }^{3-5}$

In this regard, the presented two sister cases of FPC with very advanced age ( 90 and 87 years old) are unique. There are reports regarding onset age among FPC, some dating back to the 70 s. However, to the best of our knowledge even after extensive literature research, there is no report of FPC ageabove 80 years. ${ }^{3,4,6-14}$ There are two possible underlying reasons to explain about elderly patients with FPC. One possibility is the acquisition of new unique genome in these siblings. ${ }^{15,16}$ The other is incidental cases with sporadic PC due to the accumulation of various risk factors, such as longstanding diabetes and passive smoking alike the present sibling cases. At present, clinical and genetic data of patients with FPC are piling up worldwide including Japan. ${ }^{17-19}$ Accumulation of PC is usually due to environmental exposure to carcinogenetic factors and genetic factors associated with PC, presumably stronger in FPC. ${ }^{19}$ Therefore, PC would develop in a young age if the members of FPC are exposed to multiple environmental risk factors. ${ }^{20}$ The environmental exposures, i.e. longstanding diabetes and passive smoking are important in the development of sporadic PC and FPC. ${ }^{21}$ As shown in Flowchart 1 , four patients in this family suffered from PC, two males, and two females. Two male patients with PC died younger than the present sisters, father and younger brother at the age of 52 and

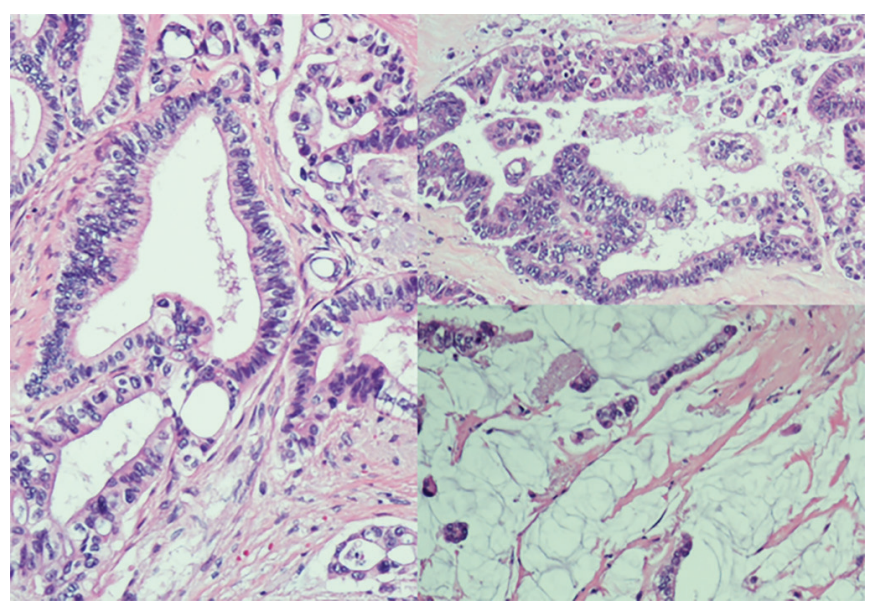

Fig. 4: Microscopic picture of pancreatic cancer (case 2) 
Flowchart 1: Familial tree in two siblings of FPC

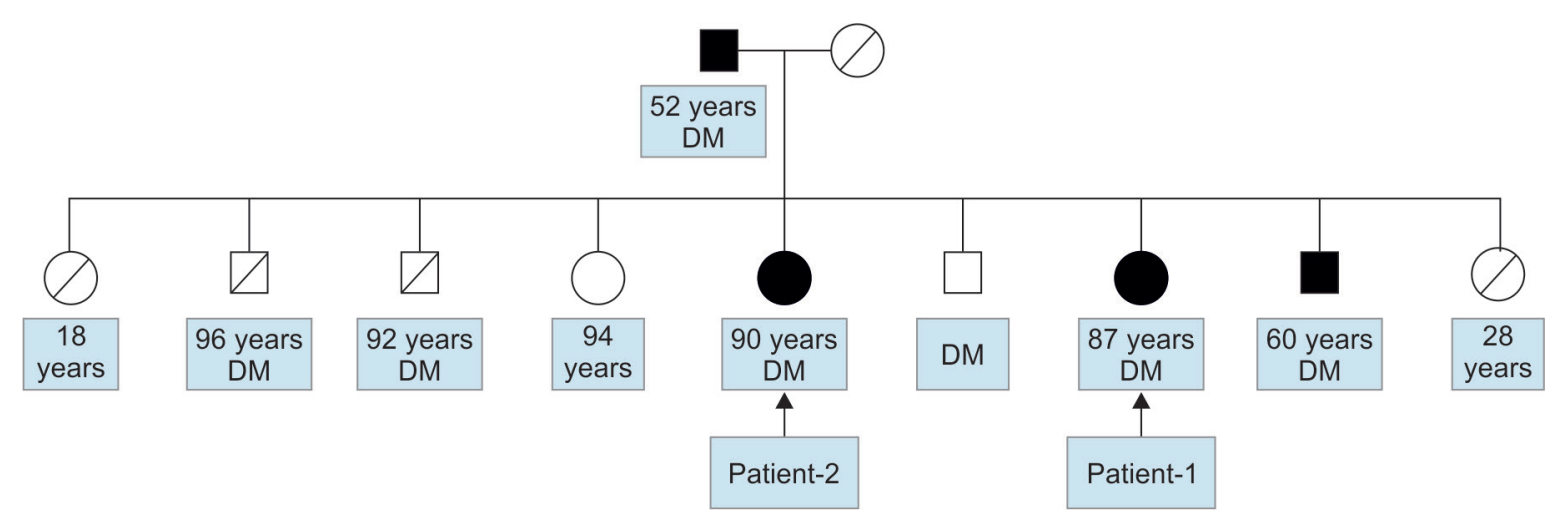

50 , respectively. Although odd index about gender and age risk factors of $\mathrm{PC}$ are not larger than other risk factors including family history, smoking, and obesity, recent new research data from Japan demonstrated a crucial role of dedifferentiationassociated epigenetic regulations in the initiation of pancreatic cancers. ${ }^{22}$ At any rate, the present case report would contribute to provide new unique subject on the research area on FPC, for example, the elucidation of risk factors of very elderly PC patients between FPC and sporadic PC.

Both patients had Hashimoto's disease. There are reports suggesting an increased risk for extrathyroidal cancers in thyroid diseases: breast, colon, melanoma, hematologic malignancies, uterus, kidney, and ovary. ${ }^{23}$ Grave's disease and high thyroid hormone level in sera, especially T3 levels, were linked to breast cancer incidence. ${ }^{24}$ However, there is no report showing its association between PC and thyroid diseases including Hashimoto's diseases. Since Hashimoto's disease is a relatively common disease as such there might be no relationship with PC. However, we may hypothesize that Hashimoto's disease delayed the onset of PC in the sisters. This should be addressed in the future.

In summary, the eldest sibling cases of FPC ever reported. The further genetic and epigenetic analysis would give us an answer to understand the underlying pathogenesis of FPC. ${ }^{25}$ In the meantime, it is essential we collect the clinical data and preserve the materials of DNA from many cases with FPC. ${ }^{26}$ It is expected that the present report should provide a new research project of FPC.

\section{References}

1. Matsubayashi H, Takaori K, et al. Familial pancreatic cancer: Concept, management and issues. World J Gastroenterol 2017; 23(6): 935-948.

2. James $T A$, Sheldon DG, et al. Risk factors associated with earlier age of onset in familial pancreatic carcinoma. Cancer 2004;101:2722-2726.

3. Ghadirian $P$, Liu G, et al. Risk of pancreatic cancer among individuals with a family history of cancer of the pancreas. Int J Cancer 2002;97:807-810.

4. http://ganjoho.jp/data/reg_stat/statistics/brochure/2017/cancer_ statistics_2017.pdf(March 2018; Accessed: November 18, 2018)

5. James TA, Sheldon DG, et al. Risk factors associated with earlier age of onset in familial pancreatic carcinoma. Cancer 2004;101:2722-2726.

6. Lin Y, Tamakoshi A, et al. Descriptive Epidemiology of Pancreatic Cancer in Japan. J Epidemiol; 1998;8:52-59.
7. Jacobson SD, Alberts SR, et al. Pancreatic cancer in the older patient. Oncology 2001;15:926-937.

8. Bellevue O, Johnson B, et al. Pancreatic cancerin the very elderly patients: Challenges and solutions. Surg Res Open J 2016;3:4-12.

9. MacDermott RP, Kramer P. Adenocarcinoma of the pancreas in four siblings. Gastroenterology 1973;65:137-139.

10. Friedman JM, Fialkow PJ. Carcinoma of the pancreas in four brothers. Birth Defects Orig Artic Ser 1976;12:145-150.

11. Reimer RR, Fraumeni JF Jr, et al. Pancreatic cancer in father and son. Lancet 1977; 2:747.

12. NmDat, Sontag SJ. Pancreatic carcinoma in brothers. Ann Intern Med 1982;97(2):282.

13. Ghadirian P, Simard A, et al. cancer of the pancreas in two brothers and one sister. Int J Pancreatol 1987;2:137-139.

14. Deborah $E$, Haeger $L$, et al. Familial pancreatic adenocarcinoma in three generations. A case report and a review of the literature. Cancer 1987;59:1661-1664.

15. Petersen GM. Familial pancreatic cancer. SeminOncol. 2016; 43:548553.

16. Chang $\mathrm{MC}, \mathrm{Wu} \mathrm{CH}$, et al. Pancreatic cancer screening in different risk individuals with family history of pancreatic cancer - a prospective cohort study in Taiwan. Am J Cancer Res 2017;7:357-369.

17. Evans JP, Burke W, et al. Familial pancreatic adenocarcinoma: association with diabetes and early molecular diagnosis. J Med Genet 1995;32:330-333.

18. Klein AP, Brune KA, et al. Prospective risk of pancreatic cancer in familial pancreatic cancer kindreds. Cancer Res 2004;64:2634-2638.

19. Dergham ST, Dugan MC, et al. Relationship of family cancer history to the expression of p53, p21WAF-1,HER-2/neu,and Kra mutation in pancreatic adenocarcinoma. Int J Pancreatol 1997;21:225-234.

20. Brune $K A$, Lau B, et al. Importance of age of onset in pancreatic cancer kindreds. J Natl Cancer Inst 2010;102:119-126.

21. Matsubayashi $H$, Maeda A, et al. Risk factors of familial pancreatic cancer in Japan: current smoking and recent onset of diabetes. Pancreas 2011;40:974-978.

22. Shibata $\mathrm{H}$, Komura $\mathrm{S}$, et al. In vivo reprogramming drives Kras-induced cancer development. Nat Commun 2018;9:2081.

23. Frohlich E, WahI R. Thyroid autoimmunity: Role of anti-thyroid antibodies in thyroid and extra-thyroidal diseases. Front Immunol 2017;8:521.

24. Goldman MB, Monson RR, et al. Cancer mortality in women with thyroid disease. Cancer Res 1990;50:2283-2289.

25. Morizane $C$, Kitano $M$, et al. Japanese familial pancreatic cancer registry with the aim to early detection of pancreatic cancer. Suizou 2017;32:23-29. (in Japanese with English Abstract)

26. Takai $E$, Yachida $S$, et al Germline mutations in Japanese familial pancreatic cancer patients. Oncotarget 2016;7:74227-74235. 